\title{
Kajian terhadap Gerakan Kebangkitan Epistemologi (Epistemological Movement) Krisis Sains Modern Richard Tarnas
}

Didih Syakir Munandar ${ }^{1}$, Nanat Fatah Natsir ${ }^{2}$, Erni Haryanti ${ }^{3}$

1,2,3Universitas Islam Negeri Sunan Gunung Djati Bandung, Indonesia

E-mail:_didihsyakir@gmail.com, nanatfatahnatsir@uinsgd.ac.id, erni_hk@uinsgd.ac.id

\section{Article Info \\ Article History \\ Received: 2021-11-20 \\ Revised: 2021-12-15 \\ Published: 2022-01-14}

Keywords:

Resurrection:

Epistemology;

The Crisis of Modern

Science;

Richard Tarnas.

\begin{abstract}
This study describes the study of the epistemological movement of the crisis of modern science by Richard Tarnas. The method used in this study uses a library research method or approach, that library research can be interpreted as a series of activities related to the methods of collecting library data, reading and taking notes and processing research materials. The results of this study indicate that modern civilization is often seen as the result of the pinnacle of human civilization, in fact it is not fully agreed upon, therefore there are many multidimensional problems, so appropriate solutions are needed for all these problems. Experts state that the way out of these problems can no longer be handled by the paradigm of modernism, so they firmly state that the world in post- or postmodernism needs another paradigm, especially in the reconstruction of educational thought. In post-industrial postmodern society, science is ultimately delegitimized, because it is proven that it cannot escape the negative effects it produces itself. The legitimacy which states that knowledge must be aimed at knowledge, in modern times cannot be fulfilled. Because knowledge turns out to be produced solely for profit alone, the norm of right and wrong no longer applies as a standard, but is pragmatic in order to generate as much profit as possible with as little funding as possible.
\end{abstract}

\begin{tabular}{l}
\hline Artikel Info \\
\hline Sejarah Artikel \\
Diterima: $2021-11-20$ \\
Direvisi: 2021-12-15 \\
Dipublikasi: $2022-01-14$
\end{tabular}

Kata kunci:

Kebangkitan; Epistemologi; Krisis Sains Modern; Richard Tarnas.

\section{PENDAHULUAN}

Perkembangan ilmu pengetahuan tidak muncul secara mendadak. Menurut (Irwansyah, 2021) bahwa ilmu pengetahuan hadir melalui suatu proses mulai dari pengetahuan sehari-hari dengan melalui pengujian secara cermat dan pembuktian dengan teliti diperoleh suatu teori, dan pengujian suatu teori bisa dilakukan dan babak terakhir akan ditemukan hukum-hukum. Filsafat menurut (Al-Attas, 2003) merupakan

\begin{abstract}
Penelitian ini menjelaskan tentang kajian terhadap gerakan kebangkitan epistemologi (epistemological movement) krisis sains modern Richard Tarnas. Metode yang digunakan dalam kajian ini menggunakan metode atau pendekatan kepustakaan (library research), bahwa studi pustaka atau kepustakaan dapat diartikan sebagai serangkaian kegiatan yang berkenaan dengan metode pengumpulan data pustaka, membaca dan mencatat serta mengolah bahan penelitian. Hasil penelitian ini menunjukkan bahwa peradaban modern seringkali dipandang sebagai hasil puncak peradaban manusia, ternyata tidak sepenuhnya disepakati kebenarannya, oleh

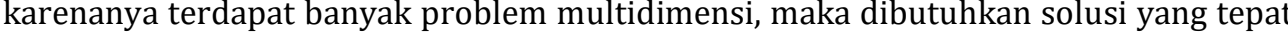
terhadap segala problem-problem tersebut. Para ahli menyatakan bahwa jalan keluar sehingga mereka dengan tegas menyatakan, dunia pada pasca atau postmodernisme membutuhkan paradigma lain, terutama dalam upaya rekonstruksi pemikiran pendidikan. Pada masyarakat postmodern pasca industri, ilmu pada akhirnya mengalami delegitimasi, karena terbukti tidak dapat menghindar dari efek negatif yang dihasilkannya sendiri. Legitimasi yang menyatakan bahwa pengetahuan harus ditujukan demi pengetahuan, pada masa modern tidak dapat dipenuhi. Karena pengetahuan ternyata dihasilkan semata-mata untuk keuntungan semata, norma benar-salah tidak lagi berlaku sebagai standar, akan tetapi pragmatis demi menghasilkan sebesar- besarnya profit dengan pendanaan sedikit mungkin.
\end{abstract} dasar-dasar tradisi intelektual yang diawali oleh filsuf-filsuf Yunani Kuno di abad ke 6 SM. Dalam perkembangannya menurut (Na'im, 2021) bahwa filsafat mengantarkan lahirnya suatu konfigurasi yang menunjukkan bagaimana cabang-cabang ilmu pengetahuan melepaskan diri dari keterkaitannya dengan filsafat, yang masing-masing secara mandiri berkembang menurut metodologinya sendiri-sendiri. 
Kajian umum maupun kritis tentang problem filsafat ilmu, pada umumnya terjadi seputar masalah yang terkait dengan kebenaran (truth), kenyataan atau fakta, dan logika (Lubis, 2014). Problem filsafat ilmu itu sendiri, bisa kita simpulkan mencakup pada beberapa problem, yaitu; pertama adalah pada problem ontologi ilmu pengetahuan itu sendiri; kebenaran ilmu pengetahuan yang berlandaskan pada norma ontologis yaitu "apa yang terjadi" dan pada eksistensi wujud atau entitas. Kedua, pada problem epistemologi ilmu pengetahuan; yaitu pembahasan terkait asal, sifat natural, sejauh mana konsep dibatasi, sumber dari sebuah asumsi berasal, kaidah landasan berfikir yang digunakan, uji sebuah validitas dan reliabilitas dilaksanakan, hingga kepada masalah kebenaran itu sendiri, terkait bagaimana proses ilmu didapatkan serta bagaimana proses sebuah metoda dapat menggapai sebuah kebenaran. Selanjutnya problem yang ketiga adalah tentang aksiologi ilmu pengetahuan; dampak pada bidang etis, bidang estetis, deskripsi tentang peran dan manfaat ilmu dalam peradaban manusia. Kesemuanya tersebut di atas, dijadikan sebagai landasan penelitian ilmu dalam filsafat barat.

Problem penelitian ilmu tersebut telah menjadi diskursus hangat dikalangan para penggiatnya, kajiannya setara diskusi tentang landasan pengembangan ilmu pengetahuan itu sendiri yakni landasan ontologis, epistemologis, dan aksiologis. Dari sekian banyak tokoh, tersebutlah salah satunya adalah Richard Tarnas, dan melalui karya tulisnya, ia ikut terlibat dalam wacana kritis epistemologi ilmu tersebut, oleh karena itu, ditegaskan pada awal penelitian ini, bahwa fokus dan pembatasan masalah kajian pada makalah ini adalah seputar kajian pemikiran Richard Tarnas sebagai salah satu tokoh filsafat kontemporer. Sedangkan metode yang dipilih dalam penyusunan makalah ini adalah pendekatan kajian pustaka terhadap buah pemikiran yang bersumber dari karya tulis berupa buku, artikel maupun kutipan terhadap hasil telaah dan analisis buah pikiran oleh para peneliti terdahulu disertai analisis.

\section{METODE PENELITIAN}

Sesuai dengan karakteristik masalah yang diangkat dalam penelitan ini maka menggunakan Metode Riset kualitatif, yaitu menekankan analisanya pada data deskriptif berupa kata-kata tertulis yang diamati. Pendekatan kualitatif penulis gunakan untuk menganalisis kajian terhadap gerakan kebangkitan epistemologi (epistemolo- gical movement) krisis sains modern Richard Tarnas.

Maka dengan sendirinya penganalisaan data ini lebih difokuskan pada Penelitian Kepustakaan (Library Research), yakni dengan membaca, menelaah dan mengkaji buku-buku dan sumber tulisan yang erat kaitannya dengan masalah yang dibahas. Metode yang digunakan dalam kajian ini menggunakan metode atau pendekatan kepustakaan (library research), menurut Zed dalam (Rahayu, 2020) bahwa studi pustaka atau kepustakaan dapat diartikan sebagai serangkaian kegiatan yang berkenaan dengan metode pengumpulan data pustaka, membaca dan mencatat serta mengolah bahan penelitian.

Jenis penelitian ini adalah penelitian kualitatif. Menurut Ibnu dalam (Nasser, 2021) penelitian kualitatif adalah suatu penelitian yang datanya dinyatakan dalam bentuk verbal dan dianalisis tanpa menggunakan teknik statistik. Berdasarkan beberapa definisi penelitian kualitatif di atas, dapat disimpulkan bahwa penelitian kualitatif adalah suatu penelitian yang datanya dinyatakan dalam bentuk verbal, tidakmenggunakan angka dan analisisnya tanpa menggunakan teknik statistik.

1. Objek Penelitian

Dalam penelitian ini objek penelitian terdiri dari 2 (dua), yaitu objek formal dan objek material (Arifudin, 2021). Objek formal dalam penelitian ini berupa data yaitu data yang berhubungan dengan kajian terhadap gerakan kebangkitan epistemologi (epistemological movement) krisis sains modern Richard Tarnas. Sedangkan objek materialnya berupa sumber data, dalam hal ini adalah kajian terhadap gerakan kebangkitan epistemologi (epistemological movement) krisis sains modern Richard Tarnas.

2. Waktu Penelitian

Penelitian ini dilaksanakan pada bulan Oktober sampai dengan Desember tahun 2021.

3. Teknik Pengumpulan Data

Pengumpulan data yang dilakukan dengan menggunakan teknik dokumentasi yaitu mengadakan survey bahan kepustakaan untuk mengumpulkan bahan-bahan, dan studi literatur yakni mempelajari bahan-bahan yang berkaitan dengan objek penelitian. Teknik pengumpulan data menurut (Bahri, 2021) mengemukakan bahwa merupakan langkah yang paling strategis dalam penelitian karena tujuan untama dari penelitian adalah mendapatkan data. Terdapat beberapa cara atau teknik dalam mengumpulkan data, diantara- 
nya adalah observasi dan dokumentasi. Sumber data yang digunakan dalam penelitian ini mencakup data primer dan sekunder. Menurut (Hanafiah, 2021) bahwa data primer adalah data yang dikumpulkan langsung dari individu-individu yang diselidiki atau data tangan pertama. Sedangkan data sekunder adalah data yang ada dalam pustaka-pustaka. Data primer dalam penelitian ini adalah bukubuku terkait kajian terhadap gerakan kebangkitan epistemologi (epistemological moveme$n t)$ krisis sains modern Richard Tarnas, dan data sekunder didapatkan dari jurnal-jurnal baik nasional maupun internasional.

4. Alat Pengumpulan Data

Dalam penelitian ini, penulis akan menggunakan metode dokumentasi sebagai alat untuk pengumpul data karena penelitian ini adalah penelitian kepustakaan. Dengan kata lain, menurut (Juhji, 2020) bahwa teknik ini digunakan untuk menghimpun data-data dari sumber primer maupun sekunder.

5. Teknik Analisis Data

Analisis data tidak saja dilakukan setelah data terkumpul, tetapi sejak tahap pengumpulan data proses analisis telah dilakukan. Penulis menggunakan strategi analisis "kualitatif", strategi ini dimaksudkan bahwa analisis bertolak dari data-data dan bermuara pada kesimpulan-kesimpulan umum. Berdasarkan pada strategi analisis data ini, dalam rangka membentuk kesimpulan-kesimpulan umum analisis dapat dilakukan menggunakan kerangka pikir "induktif". Menurut (Sugiyono, 2015) bahwa metode pembahasan menggunakan metode deskriptif-analisis, yaitu menjelaskan serta mengelaborasi ide-ide utama yang berkenaan dengan topik yang dibahas. Kemudian menyajikannya secara kritis melalui sumbersumber pustaka primer maupun skunder yang berkaitan dengan tema.

6. Prosedur Penelitian

Data pada penelitian ini dicatat, dipilih dan kemudian diklasifikasikan sesuai dengan kategori yang ada. Pendekatan yang digunakan adalah pendekatan deskriptif analitis. Menurut (Marantika, 2020) bahwa deskriptif analitis (descriptive of analyze research), yaitu pencarian berupa fakta, hasil dari ide pemikiran seseorang melalui cara mencari, menganalisis, membuat interpretasi serta melakukan generalisasi terhadap hasil penelitian yang dilakukan. Prosedur penelitian ini adalah untuk menghasilkan data deskriptif yang berupa data tertulis setelah melakukan analisis pemikiran (content analyze) dari suatu teks. Setelah penulis mengumpulkan bahan-bahan yang berhubungan dengan masalah yang akan di bahas dalam penelitian ini, kemudian penulis menganalisis dan menarasikan untuk diambil kesimpulan.

\section{HASIL DAN PEMBAHASAN}

Dalam pembahasan ini akan dibahas tentang Biografi Richard Tarnas, dan The Crisis of Modern Science.

\section{Biografi Richard Tarnas}

Richard Tarnas adalah seorang sejarawan budaya dan astrolog yang dikenal dengan karya-karya tulisannya. Tarnas adalah profesor filsafat dan psikologi di California Institute of Integral Studies, dan direktur pendiri program pascasarjana di bidang Filsafat, Kosmologi, dan Kesadaran, Tarnas lahir pada 21 Februari 1950 di Jenewa, Swiss, dari orang tua Amerika. Ayahnya, juga bernama Richard Tarnas, bekerja sebagai pengacara kontrak pemerintah, mantan presiden Michigan Federal Bar Association, dan profesor hukum. Ibunya, Mary Louise, adalah seorang guru dan ibu rumah tangga. Anak tertua dari delapan bersaudara, ia dibesarkan di Detroit, Michigan, di mana ia belajar bahasa Yunani, Latin, dan Klasik di Sekolah Tinggi dan Akademi Jesuit Universitas Detroit.

Pada tahun 1968 Tarnas masuk Harvard, lulus dengan gelar A.B. cum laude pada tahun 1972. Ia menerima gelar Ph.D. dari Saybrook Institute pada tahun 1976 dengan tesis tentang terapi psikedelik. Pada tahun 1974 Tarnas pergi ke Esalen di California untuk belajar psikoterapi dengan Stanislav Grof. Dari 1974 hingga 1984 ia tinggal dan bekerja di Esalen Institute di Big Sur, California, mengajar dan belajar dengan Grof, Joseph Campbell, Gregory Bateson, Huston Smith, Elizabeth Kübler-Ross, dan James Hillman. Dia juga menjabat sebagai direktur program dan pendidikan Esalen. Jeffrey Kripal mencirikan Tarnas sebagai penjaga gerbang literal dan figuratif Esalen.

Dari tahun 1980 hingga 1990, Tarnas menulis The Passion of the Western Mind: Understanding the Ideas That Have Shaped Our World View, sebuah narasi sejarah pemikiran Barat yang menjadi buku terlaris dan tetap digunakan di universitas pada tahun 2000. Buku ini sangat diakui oleh Joseph Campbell, Huston Smith, Stanislav Grof, John E. Mack, Stanley Krippner, Georg Feuerstein, David 
Steindl-Rast, John Sculley, Robert A. McDermott, Jeffrey Hart, Gary Lachman, dan lainnya.

Tarnas adalah direktur pendiri program Filsafat, Kosmologi, dan Kesadaran di Institut Studi Integral California (CIIS), di mana ia tetap menjadi anggota fakultas inti pada tahun 2020, Buku kedua Tarnas, Prometheus the Awakener, diterbitkan pada tahun 1995, berfokus pada sifat-sifat astrologi dari planet Uranus, menggambarkan "cara luar biasa pola astrologi tampak bertepatan dengan peristiwa atau pola takdir dalam kehidupan individu dan masyarakat". Tarnas menunjukkan bahwa karakteristik yang terkait dengan sosok mitologis Uranus tidak cocok dengan sifat astrologi planet Uranus, dan bahwa identifikasi yang lebih tepat akan melibatkan sosok mitologis Prometheus.

Pada tahun 2006, Tarnas menerbitkan buku ketiganya, Cosmos and Psyche: Intimations of a New World View. Ia mengklaim bahwa peristiwa-peristiwa besar dalam sejarah budaya Barat berkorelasi secara konsisten dan bermakna dengan posisi sudut yang diamati dari planet-planet. Buku ini mendapat ulasan yang baik di majalah Tikkun, di jurnal antroposofis, dan di majalah web Reality Sandwich (oleh Daniel Pinchbeck), tetapi digeser di Wall Street Journal, Tarnas ditampilkan dalam film 2006 Entheogen: Awakening the Divine Within, sebuah film dokumenter tentang menemukan kembali kosmos yang terpesona di dunia modern.

Pada tahun 2007 sekelompok lima puluh sarjana dan peneliti di San Francisco Bay Area membentuk Kolektif Penelitian Pola Dasar untuk mengejar penelitian dalam kosmologi pola dasar. Sebuah jurnal online, Archai: The Journal of Archetypal Cosmology, diedit oleh Keiron LeGrice dan Rod O'Neal, dimulai setahun kemudian, berdasarkan orientasi penelitian dan metodologi yang ditetapkan dalam Cosmos and Psyche. Anggota dewan penasihat termasuk Christopher Bache, Jorge Ferrer, Stanislav Grof, Robert A. McDermott, Ralph Metzner, dan Brian Swimme. Kontributor termasuk Keiron Le Grice, Richard Tarnas, Stanislav Grof, dan Rod O'Neal.

Pada tahun 2008 Tarnas diundang untuk berbicara kepada anggota Parlemen Belanda tentang menciptakan masyarakat yang berkelanjutan, dan Pada tahun 2007 John Cleese dan Tarnas memberikan beberapa kuliah umum bersama di Institut Esalen di Big Sur,
California dan di Santa Barbara. Ceramah tersebut membahas tentang mendapatkan kembali hubungan dengan yang suci di dunia modern. Cleese dan Tarnas kemudian mengajar seminar di CIIS yang bertajuk "The Comic Genius: A Multidisipliner Approach", Astronot Amerika Susan Helms mengutip Tarnas' The Passion of the Western Mind sebagai salah satu dari lima 'buku klasik Amerika' yang mengilhami karirnya sebagai astronot.

\section{The Crisis of Modern Science}

Richard Tarnas dikenal dengan teorinya, yang menyatakan bahwa sains modern yang mainstreamnya berkiblat ke barat, memiliki banyak celah yang masih lemah, serta tidak terbukti mampu berhasil memberikan solusi pemecahan terhadap problem-problem kehidupan yang mendasar sekalipun, oleh karenanya ia menggagas satu ide "mainstream" baru yang lebih baik dan benar, dalam tulisan (Sofyan, 2015) menyatakan, bahwa Tahun 1991, Tarnas menulis buku dengan judul "The Passion of the Western Mind", yang dalam buku tersebut ada satu bab yang menarik perhatian publik, dengan judul "The Crisis of Modern Science". Tulisanya meresume dan merinci kesalahan-kesalahan ilmu Barat sekuler dalam buku tarnas tersebut, di antaranya, Pertama, Ide dasar ilmu pengetahuan di Barat adalah "space", "matter", "causality" dan "observation", akan tetapi ternyata semuanya tidak terbukti benar. Pandangan yang sekarang berlaku adalah space sesungguhnya adalah terbatas (finite), akan tapi lepas; serta juga pada ternyata bentuknya lengkung/ tidak linier, sehingga garis edar/orbit bendabenda angkasa berbentuk elips, bukan karena tertarik oleh gaya gravitasi ke matahari, tapi memang bentuknya lengkung. Kemudian kini berlaku empat dimensi "space time", bukan hanya tiga seperti pada Eucledian geometry. Kedua, pendapat Kant yang menyatakan bahwa jagat raya bukan jagat raya yang sebenarnya, akan tapi merupakan jagat raya yang diciptakan oleh manusia. Ketiga, deterministik Newton kehilangan dasar, maka orang mulai dengan "stochastic". Keempat, partikelpartikel sub atomik terbuka untuk interprettasi spiritual. Kelima, prinsip "uncertainty" sebagaimana yang ditemukan oleh Heinsberg. Keenam, kerusakan ekologi dan atmosfir yang menyeluruh yang disebutnya "planetary ecological crisis" 
Sedangkan menurut (Baihaki, 2006), secara komprehensif Tarnas mencoba menjelaskan keadaan krisis Sains Barat Modern (SBM), disertai alasan-alasan yang sangat mendasar, dan sulit dibantah. penjelasannya dapat disusun menjadi 5 bagian, sebagai berikut Pertama, bahwa 4 teori dasar SBM terbukti keliru (controverted), keempat teori dasar tersebut adalah ruang (space), materi (matter), observasi dan kausalitas. Ruang yang awalnya terdiri dari tiga dimensi harus menjadi empat dimensi, maka menjadi ruang waktu. Didapati ruangpun bertopografi, dan di dalam topografi cahaya berjalan dengan lengkung, bukan linier. Koordinat Cartesiannewtonian perlu ditambah waktu. Materi yang katanya solid seperti diungkapkan oleh Demokritos, ternyata di dalamnya terdapat kehampaan seperti pada atom bohr. Observasi kini diragukan kemantapannya, dan mulai disadari bahwa di depan mata setiap orang ada "lensa" yang di bentuk oleh tata nilai yang dianut, pengalaman, aspirasi, harapan, trauma-trauma, dan sebagainya. Maka setiap orang memiliki "cognitive syndrome" nya sendiri. Adapun kausalitas yang kini berlaku ternyata terlalu simplisistik, sebagai akibat dari observasi yang terbatas kemampuannya ("terpola").

Oleh karenanya menurut Tarnas, akibat kesalahan tersebut, berdampak pada kerusakan yang tidak hanya pada manusia saja, akan tetapi terjadi menyeluruh pada alam maupun pada masyarakat secara umum. Contohnya terjadi pada rusaknya alam seperti rusak lingkungan atau ekologi pada pencemaran di air, udara, tanah, sehingga terjadi dampak buruk pada kehidupan tumbuhan dan hewan, sehingga terjadi kerusakan di muka bumi. Terbukti SBM tidak memiliki kemampuan untuk memperbaiki diri sendiri, meskipun saintifik SBM menjadi semakin proporsional. Kedua, terjadi kesalahan epistemologis. Dasar -dasar epistemologisnya dinyatakan keliru karena yang tampak kepada kita itu bukan jagat raya yang sebenarnya, akan tetapi jagat raya yang sebagaimana dipertanyakan oleh orang (observer). Oleh karenanya beberapa hal dalam paradigm teori sebab-akibat harus direvisi, seperti deterministic Newtonian, kecerdasan electron, prinsip ketidak-pastian (Heisenberg), dan sebagainya. Ketiga, "Order" newtonian telah runtuh, kini terbuka bagi siapapun untuk melukiskan order dari jagat raya ini. Keempat, keperilakuan partikelpartikel sub-atomik ternyata terbuka untuk adanya interpretasi spiritual. Kelima, akibat dari semua hal ini adalah runtuhnya kepercayaan kepada Sains Barat Modern.

Para ilmuwan Sains Barat Modern berada dalam kekalutan atau "kalang-kabut", mereka, yaitu orang barat mulai sadar, bahwa mereka telah menyingkirkan agama dalam kehidupan mereka dan beralih kepada sains yang penuh dengan "kepastian" itu. Menurut (Arifudin, 2020) bahwa sekarang ternyata sains itu juga dirundung oleh prinsip ketidakpastian. Sebagai akibat dari tidak benarnya kemampuan observasi manusia. Tarnas mengatakan bahwa SBM perlu dire-evaluasi sepenuh hati.

\section{SIMPULAN DAN SARAN}

\section{A. Simpulan}

Berdasarkan pemaparan pada penelitian ini dapat disimpulkan bahwa krisis Sains Modern yang digagas oleh Richard Tarnas memberikan pemahaman bahwa: (1) 4 teori dasar SBM terbukti keliru (controverted), keempat teori dasar tersebut adalah ruang (space), materi (matter), observasi dan kausalitas.; (2) Dianutnya pendapat Kant "jagat raya, bukan jagat raya yang sebenarnya sebagaimana terdapat dalam pikiran dan indera manusia" jadi, terjadi kesalahan epistemologis. Dasar-dasar epistemologisnya dinyatakan keliru karena yang tampak kepada kita itu bukan jagat raya yang sebenarnya. (3) deterministik newton kehilangan dasar, orang mulai dengan "stochastic"; dan kini terbuka bagi siapapun untuk melukiskan order dari jagat raya ini, (4), Keperilakuan partikelpartikel sub-atomik ternyata terbuka untuk adanya interpretasi spiritual. Prinsip "uncertainty" sebagaimana dikemukakan oleh Heisenberg; (5) Kerusakan ekologi yang menyeluruh (planetary ecological crisis). Akibat dari semua hal ini adalah runtuhnya kepercayaan kepada Sains Barat Modern.

\section{B. Saran}

Pembahasan terkait penelitian kajian terhadap gerakan kebangkitan epistemologi (epistemological movement) krisis sains modern Richard Tarnas dalam penelitian ini masih sangat terbatas dan membutuhkan banyak masukan. Saran untuk penulis selanjutnya adalah mengkaji lebih dalam dan secara komprehensif terkait kajian terhadap gerakan kebangkitan epistemologi (epistemological movement) krisis sains modern Richard Tarnas. 


\section{DAFTAR RUJUKAN}

Al-Attas. (2003). Filsafat dan Praktik Pendidikan Islam, terj. Hamid Fahmi dkk. Bandung: Mizan.

Arifudin, 0. (2020). Psikologi Pendidikan (Tinjauan Teori Dan Praktis). Bandung: Widina Bhakti Persada.

Arifudin, 0. (2021). Manajemen Strategik Teori Dan Implementasi. Banyumas: Pena Persada.

Asmedy, A. (2021). Perbandingan Hasil Belajar Matematika Siswa yang diajar dengan Model Pembelajaran Possing Problem Berkelompok dan Metode Ceramah. Jurnal Inovasi, Evaluasi Dan Pengembangan Pembelajaran (JIEPP), 1(2), 69-75. https://doi.org/10.54371/jiepp.v1i2.107

Bahri, A. S. (2021). Pengantar Penelitian Pendidikan (Sebuah Tinjauan Teori dan Praktis). Bandung: Widina Bhakti Persada.

Baihaki. (2006). Sains Modern: Kontemplasi dan Realita. Jakarta: Baihaki.

Hanafiah, H. (2021). Pelatihan Software Mendeley Dalam Peningkatan Kualitas Artikel Ilmiah Bagi Mahasiswa. Jurnal Karya Abdi Masyarakat, 5(2), 213-220.

Irwansyah, R. (2021). Perkembangan Peserta Didik. Bandung : Widina Bhakti Persada.

Juhji. (2020). Manajemen Humas Sekolah. Bandung: Widina Bhakti Persada.
Lubis. (2014). Epistemologi Ilmu Pengetahuan Dan Relevansinya Dalam Studi Al-Qur'an. Hermeunetik, 8(1), 39-56.

Marantika, N. (2020). Manajemen Humas Sekolah. Bandung: Widina Bhakti Persada Bandung.

Na'im, Z. (2021). Manajemen Pendidikan Islam. Bandung: Widina Bhakti Persada.

Nasser, A. A. (2021). Sistem Penerimaan Siswa Baru Berbasis Web Dalam Meningkatkan Mutu Siswa Di Era Pandemi. Biormatika: Jurnal Ilmiah Fakultas Keguruan Dan Ilmu Pendidikan, 7(1), 100-109.

Rahayu, Y. N. (2020). Program Linier (Teori Dan Aplikasi). Bandung : Widina Bhakti Persada.

Rinjani, C., Wahdini, F. I., Mulia, E., Zakir, S., \& Amelia, S. (2021). Kajian Konseptual Model Pembelajaran Word Square untuk Meningkatkan Hasil Belajar Siswa.Jurnal Inovasi, Evaluasi Dan Pengembangan Pembelajaran (JIEPP), 1(2), 52-59. https://doi.org/10.54371/jiepp.v1i2.102

Sofyan. (2015). Merenungi Kenyataan dengan Nalar. Jakarta: Kompasia.

Sugiyono. (2015). Metode Penelitian Pendidikan (Pendekatan Kuantitatif,. Kualitatif dan $R \& D)$. Bandung : CV. Alfabeta. 